\title{
Mover el marco, ¿subvertir la historia de la Historia? Comenta- rio bibliográfico sobre el libro La Segunda Marquetalia, la lucha sigue, escrito por el guerrillero Iván Márquez (2020)
}

Angélica Pineda-Silva ${ }^{1}$

El libro que desde la clandestinidad y la espesura de las montañas colombianas escribe Iván Márquez, La Segunda Marquetalia, la lucha sigue, fue publicado en formato digital en marzo de 2020 y se encuentra disponible para descarga libre. $^{2}$

Tanto el autor como el libro resultan emblemáticos si se tiene en cuenta que Márquez se desempeñó como jefe del equipo negociador de las Fuerzas Armadas Revolucionarias de Colombia Ejército del Pueblo, FARC-EP, en los diálogos de paz que se llevaron a cabo en La Habana, Cuba, y que fueron refrendados en Bogotá en noviembre de 2016 entre esta guerrilla y el Estado de Colombia en cabeza de Juan Manuel Santos. Pero no solo eso, Márquez además de ser un intelectual y curtido guerrillero, tiene una amplia trayectoria como líder social y político. En la década de los '80, tras los Acuerdos de cese al Fuego, Paz y Tregua firmados el 28 de marzo de 1984 entre las FARC y el Gobierno del entonces presidente Belisario Betancur en La Uribe, Meta, Iván Márquez fue elegido Representante a la Cámara por el departamento del Caquetá con el partido Unión Patriótica, parti- do que luego sería exterminado con el beneplácito del Estado colombiano en lo que se llamó de manera eufemística El Baile Rojo. Tras esta cruel y despiadada felonía en la que fueron asesinados alrededor de cinco mil militantes de la UP, líderes y liderezas sociales, Marquez decide volver al monte, o en jerga fariana, enguerrillerarse.

No es casualidad entonces que treinta y cuatro años después, el que fuera plenipotenciario de las FARC-EP en los Acuerdos de La Habana, Iván Márquez, decidiera, ante una nueva traición del Estado colombiano, volver a enguerrillerarse aduciendo el «derecho universal de los pueblos del mundo a la rebelión, al alzamiento armado contra la opresión» (Márquez, 2020, p. 184).La Segunda Marquetalia, la lucha sigue, tiene una característica fundamental: está escrito desde la clandestinidad, lo que implica una subversión del discurso hegemónico sobre los hechos, podríamos decir, la otra cara de la moneda de los acontecimientos en una narrativa que desafía, o por lo menos se encuentra a contra corriente de la oficialidad del discurso. En este punto vale la pena pensar entonces en una historia escrita

\footnotetext{
${ }^{1}$ Universidad Autónoma Metropolitana Unidad Xochimilco, México. Contacto: anpinedasilva@hotmail.com

${ }^{2}$ http://farc-ep.net/wp-content/uploads/2020/03/diagramacion_s_m_final_web.pdf
} 
desde abajo, en el sentido que utiliza Ferraroti (2007), es decir, una historia que permite la emergencia de una realidad que se encuentra en relación directa con la acción o lo que es lo mismo, con los hechos acontecidos. $\mathrm{Al}$ respecto también vale la pena rescatar la conceptualización de la damnatio memoriae, o condenación de la memoria, práctica que se remonta a la Roma antigua y en la cual tras la muerte del enemigo, se obligaba a su olvido eliminando cualquier rastro de su vida y su recuerdo; misma práctica que pareciera reactualizarse para instalarse desde el Estado de Colombia frente a la memoria fariana.

La historia de Colombia contada desde su oficialidad se ha construido con «los episodios más sangrientos de la historia del país, aquellos que, de manera más evidente, han sucumbido a [una] modificación de la realidad a favor del beneficio de los poderosos. Así, la Masacre de las Bananeras -quizá el caso más emblemático y paradigmático en este sentido, en el que las cifras oscilaban entre los ocho o nueve muertos, según informaciones del gobierno, y las más de tres mil víctimas según las versiones no oficiales- marca un hito en esta cuestión» (Capote, 2016, p. 43). $\mathrm{Al}$ igual que este desastroso e infausto pasaje en la Historia de Colombia ocurrido en 1928, el Estado de Colombia aún hoy en día se niega a reconocer su responsabilidad en la perpetración y perpetuación del conflicto armado, por lo que siguen siendo excluidas de manera reiterativa las voces contrarias a la fuerza del Estado. Como mencionara
Alfredo Molano (2015): en el monopolio de la versión oficial, el otro ya está condenado como monstruo; otro que para el caso particular resultan ser las FARC-EP.

En sociedades como la colombiana, polarizada por efecto de una sistemática construcción de héroes y villanos, desnaturalizar la presencia y la lectura del marco por medio del cual se nos impone una interpretación de los hechos violentos implica un cambio de mirada, de paradigma; por ello resulta tan significativa la aproximáción a $\mathrm{La} S e$ gunda Marquetalia, la lucha sigue, pues en todo caso sus páginas contienen un anverso del discurso hegemónico imperante.

El documento de 342 cuartillas tiene una variopinta forma en su construcción, así, se encuentran narrativas de corte testimonial contadas en primera persona por Iván Márquez, como por ejemplo la travesía que daría origen al realzamiento armado el 3 de julio de 2018, noche en la que él junto a otros guerrilleros emprendieron la marcha desde la región de El Pato hacia el oriente colombiano. «Atrás quedó sin objetivo el despliegue del Batallón 22 de contraguerrilla Diosa del Chairá y del Batallón de alta montaña de Balsillas; y también el comando de francotiradores que quería matarnos... En tierra, los radios de las milicias campesinas -que son los ojos de la guerrilla- peteteaban ${ }^{3}$ para comunicar las novedades» (Márquez, 2020 , p. 25). Otros sucesos de corte testimonial son narrados en tercera persona cayendo el protagonismo en varios

\footnotetext{
${ }^{3}$ Petetear en este caso refiere a hacer una labor de inteligencia siguiendo las noticias radiales para dar parte a la guerrilla de los movimientos y avanzadas del ejército.
} 
comandantes farianos de la Segunda Marquetalia -como por ejemplo Jesús Santrich, Oscar Montero y Edison Romaña-, pero conservándose el estilo narrativo anecdótico.

También el texto «incluye desconocidas piezas de archivo de la vida interna de las FARC-EP, que dan noticia, por ejemplo, de cómo fueron los últimos tres años de vida del comandante Manuel Marulanda Vélez» (Márquez, 2020, p. 19), revelándose un pasaje bastante oscuro de traiciones al interior de las FARC-EP, pues no de otra manera se explicaría la desaparición del cuerpo inerte del comandante Marulanda ordenado por Rodrigo Londoño, Timochenko -actual presidente del partido político Fuerza Alternativa Revolucionaria del Común- y ejecutado por Carlos Antonio Lozada -actual senador por el mismo partido-, pasaje que en todo caso deja más preguntas que respuestas. Además, se incluyen misivas epistolares dirigidas a la ONU, garantes y veedores nacionales e internacionales, Comisión de Paz del Senado de la República de Colombia, dirigentes políticos, entre otros, documentos de carácter público y sobre los cuales se puede constatar su veracidad documental, remarcándose las razones de volver a la lucha armada, como es el caso de esta carta dirigida a la Comisión de Paz del Senado: «sin eufemismos y en lenguaje franco: lo esencial del Acuerdo de Paz de la Habana ha sido traicionado. El Congreso anterior hundió la Reforma Política y las Circunscripciones Territoriales Especiales de Paz. No se aplicó plenamente la amnistía; todavía quedan guerrilleros presos. Cinco años después de lograr el primer Acuerdo Parcial no hay titulaciones de tierras, ni fondo de tres millones de hectáreas para los que no las tienen, ni nada que signifique dignificación de la vida en el campo...» (Márquez, 2020, p. 37).

Hay también dos entrevistas, una concedida por Iván Márquez al periódico colombiano El Espectador, y otra concedida por Márquez y Jesús Santrich al diario alemán junge Welt, en esta última los dirigentes farianos mencionan que «frente a regímenes de terror no se les puede negar a los pueblos el derecho que tienen a la rebelión en todas sus modalidades. No se les puede condenar a los pueblos a que para que sus luchas tengan legitimidad se deban enfrentar a la represión con los pechos desnudos y con vocación de mártires» (Márquez, 2020, p. 314). En este sentido, resulta muy interesante resaltar que por medio de las anécdotas narradas se enaltece la solidaridad campesina, así como la sabíduría de los pueblos indígenas, y si leemos entre líneas, también podemos cernir en la espesura de las trochas y los montes andados, la belleza de los paisajes naturales, la preparación de recetas culinarias y la cotidiana hermandad fariana que se teje a la vez que la férrea convicción de cambiar a una estrategia que solo responderá a la ofensiva, para parar con ello los enfrentamientos fraticidas entre hermanos y hermanas de clase mientras la oligarquía colombiana se sigue cebando a costa de la miseria del pueblo colombiano; así, también se encuentran apartados más de corte panfletario o de manifiesto en los que se explicita un llamamiento a la organización social y unidad del movimiento popular en sintonía con el sueño de la unidad latinoamericana, a la 
vez que se declara que las FARC de La Segunda Marquetalia seguirán «siendo la misma guerrilla protectora del medio ambiente, de la selva, de los ríos, de la fauna» (Márquez, 2020, p. 265) con lo que queda bastante clara su férrea oposición al fracking .

En síntesis, el libro es una fuente documental importante para todo aquel que -como es mi caso- se sienta compelido a profundizar, investigar y comprender el conflicto armado colombiano y el movimiento fariano, pues se puede aproximar un análisis contextual profundo que va desde los últimos años de vida del comandante en jefe Manuel Marulanda Vélez, pasa por las negociaciones y firma del Acuerdo de Paz de La Habana, la Décima Conferencia Guerrillera, la complejidad de la dejación de las armas que finalmente se convertiría en entrega de las mismas, la inseguridad jurídica evidenciada con la captura de Jesús Santrich en lo que Iván Márquez denonimó como un montaje judicial o entreampamiento urdido por el fiscal general de Colombia, Nestor Humberto Martínez, y la DEA, las discusiones y desaveniencias en el Congreso Constitutivo de las FARC como partido político, y finalmente, la decisión de varios cuadros importantes de volver al monte para enguerrillerarse.

Es importante recordar que desde la década de los años '20 del siglo pasado han existido en varios lugares del territorio colombiano luchas sociales por la repartición de la tierra, y pese a que han habido ciertos avances, aún no se ha logrado concretar una reforma agraria que beneficie mayormente a la población campesina, si bien ese fue el primer punto acordado en los diálogos de paz, como menciona el autor del libro. Inaugurada la década de lo que en Colombia se llama época de La Violencia con el magnicidio del líder liberal Jorge Eliecer Gaitán en 1948 y escapando de la represión estatal y de las masacres de hacendados y terratenientes, miles de campesinas y campesinos se organizaron y se fueron para el monte dando nacimiento oficial en 1964 a las FARC-EP (Molano, 2017). Este punto es de vital importancia porque tenemos entonces una circularidad de la violencia, no existiendo una distinción clara y tajante del agente víctima y del agente victimario, pues como se menciona, la guerrilla de las FARC-EP se fundó con el propósito de defender la vida campesina de la violencia estatal apoyada desde sus inicios tanto por las fuerzas militares como por ejércitos privados los cuales se denominan en Colombia fuerzas paramilitares. Vale la pena entonces no perder de vista que si bien las FARCEP son reconocidas como agentes victimizantes, también fueron y siguen siendo gravemente victimizados por el estado colombiano, lo que obliga a complejizar las categorias de análisis pues los lugares de vícitima y victimario no son estáticos. En todo caso, el libro deja una sensación de preguntas suspendidas que cabalgan en medio de la certeza de que la Segunda Marquetalia se alza como una «fuerza político militar con estructura de ejército y de partido, un partido marxista-leninista y bolivariano que sigue el legado del comandante Manuel Marulanda Vélez» (Márquez, 2020, p. 313). 


\section{Referencias bibliográficas}

Capote, V. (2016). Reescribir la violencia: narrativas de la memoria en la literatura femenina colombiana. Bruselas, Bélgica: P.I.E. Peter Lang.

Ferrarotti, F (2007). Las historias de vida como método. En: Convergencia. Revista de Ciencias, pp. 15-40. Toluca, México: Universidad Autónoma del Estado de México.

Márquez, I. (2020). La Segunda Marquetalia, la lucha sigue, recuperado de http://farc-ep.net/wp-content/ uploads/2020/03/diagramacion_s m_final_web.pdf

Molano, A. (2017). Trochas y fusiles. Bogotá, Colombia: Debolsillo.

Molano, A. (2015). Panel Memorias, relatos y comunicación, en Cumbre Mundial de arte y Cultura para la Paz de Colombia. Bogotá, Colombia: IDARTES. 